\title{
Subnanometer Fusion Pores in Spontaneous Exocytosis of Peptidergic Vesicles
}

\author{
Nina Vardjan, ${ }^{1,2}$ Matjaž Stenovec, ${ }^{1,2}$ Jernej Jorgačevski, ${ }^{2}$ Marko Kreft, ${ }^{1,2}$ and Robert Zorec ${ }^{1,2}$ \\ ${ }^{1}$ Celica Biomedical Center, 1000 Ljubljana, Slovenia, and ${ }^{2}$ Laboratory of Neuroendocrinology-Molecular Cell Physiology, Institute of Pathophysiology, \\ Medical School, University of Ljubljana, 1000 Ljubljana, Slovenia
}

Kiss-and-run exocytosis, consisting of reversible fusion between the vesicle membrane and the plasma membrane, is considered to lead to full fusion after stimulation of vesicles containing classical transmitters. However, whether this is also the case in the fusion of peptidergic vesicles is unknown.

Previously, we have observed that spontaneous neuropeptide discharge from a single vesicle is slower than stimulated release, because of the kinetic constraints of fusion pore opening. To explore whether slow spontaneous release also reflects a relatively narrow fusion pore, we analyzed the permeation of FM 4-64 dye and HEPES molecules through spontaneously forming fusion pores in lactotroph vesicles expressing synaptopHluorin, a $\mathrm{pH}$-dependent fluorescent fusion marker. Confocal imaging showed that half of the spontaneous exocytotic events exhibited fusion pore openings associated with a change in synaptopHluorin fluorescence but were impermeable to FM 4-64 and HEPES. Together with membrane capacitance measurements, these findings indicate an open fusion pore diameter $<0.5 \mathrm{~nm}$, much smaller than the neuropeptides. In stimulated cells, $>70 \%$ of exocytotic events exhibited a larger, FM 4-64-permeable pore ( $>1$ $\mathrm{nm}$ ). Interestingly, capacitance measurements showed that the majority of exocytotic events in spontaneous and stimulated conditions were transient. Stimulation increased the frequency of transient events and the fusion pore dwell time but decreased the fraction of events with lowest measurable fusion pore.

Kiss-and-run is the predominant mode of exocytosis in resting and in stimulated peptidergic vesicles. Stimulation prolongs the effective opening of the fusion pore and expands its primary subnanometer diameter to enable hormone secretion without full fusion.

Key words: exocytosis; neuroendocrine; peptidergic release; fusion pore; optical imaging; pore conductance

\section{Introduction}

The release of neurotransmitters and hormones from the secretory vesicles of neurons and neuroendocrine cells is mediated by exocytosis, leading to the formation of a fusion pore between the vesicle and the plasma membranes. Vesicle cargo can be released through the pore by two mechanisms. The fusion pore either expands, causing the vesicle membrane to flatten into the plasma membrane (full fusion exocytosis) (Heuser and Reese, 1973), or reversibly closes, allowing the vesicle to retain its integrity and residual cargo ("kiss-and-run" exocytosis) (Ceccarelli et al., 1973; Alvarez de Toledo et al., 1993; Fesce et al., 1994).

The fusion pore dynamics of vesicles undergoing stimulated exocytosis has been studied extensively with electrophysiological, electrochemical, and fluorescence techniques (Lindau and Alvarez de Toledo, 2003). In vesicles undergoing spontaneous exo-

Received Jan. 26, 2007; revised March 5, 2007; accepted March 21, 2007.

This work was supported by Grant P3 310381 from the Ministry of Education, Sciences, and Sports of the Republic of Slovenia; National Institutes of Health Grant NS36665; European Commission (EC) Grant QLG3 2001-2004; EC support Dynamics of Extracellular Glutamate CLG3-CT-2001-02004; and EC GROWBETA QLG1-CT-2001-02233. We thank Dr. Gero Miesenböck (Sloan-Kettering Institute, Memorial Sloan-Kettering Cancer Center, New York, NY) for the generous gift of spH plasmid construct and Dr. Saša Jenko and Miha Pavšič (Jožef Stefan Institute, Ljubljana, Slovenia) for help in the analysis of molecular surface models. We thank Sonja Grilc for continuous support.

Correspondence should be addressed to Dr. Robert Zorec, Professor, Laboratory of NeuroendocrinologyMolecular Cell Physiology, Institute of Pathophysiology, Zaloška 4, 1000 Ljubljana, Slovenia. E-mail: robert.zorec@mf.uni-lj.si.

DOI:10.1523/JNEUROSCI.0351-07.2007

Copyright $\odot 2007$ Society for Neuroscience $\quad 0270-6474 / 07 / 274737-10 \$ 15.00 / 0$ cytosis, however, the mechanism of the formation, expansion, and resealing of the fusion pore with the plasma membrane is unclear. For decades, spontaneous exocytosis, although a lowprobability process, was thought to exhibit elementary properties similar, if not identical, to those of stimulated exocytosis (Katz, 1969). However, recent studies suggest that the exocytotic apparatus at rest differs from that under stimulation in many respects, including distinct protein requirements for vesicle trafficking (Wucherpfennig et al., 2003), fusion (Deitcher et al., 1998; Schoch et al., 2001; Sara et al., 2005), recycling (Sara et al., 2005), and the kinetics of vesicular content discharge (Stenovec et al., 2004).

In neuroendocrine cells, stimulated discharge of vesicle content is some 10-20 times faster than spontaneous discharge (Stenovec et al., 2004), indicating differences in the fusion pore properties under resting and stimulated conditions. In particular, electrophysiological measurements revealed regular repetitive transient fusion pore openings ("the pulsing pore") (Stenovec et al., 2004), suggesting that flickering activity of the fusion pore may be the constraint that causes slow release of vesicle content in resting neuroendocrine cells. However, the slower release might also reflect a narrow fusion pore under nonstimulated conditions. Recent findings point to the possibility that exocytosis without release of vesicle cargo occurs before delivery of the stimulus (Rahamimoff and Fernandez, 1997; Stenovec et al., 2004).

In this study, we tested the hypothesis that peptide vesicles at 
rest are engaged in exocytosis, yielding fusion pores of subnanometer diameters, too small for discharge of relatively large peptide hormones. For these studies, we used isolated rat anterior pituitary lactotrophs, which secrete prolactin (Walker and Farquhar, 1980) and are well suited for studying exocytosis (Angleson et al., 1999; Stenovec et al., 2004). Vesicle fusion was monitored by confocal microscopy in resting and stimulated lactotrophs expressing synaptopHluorin $(\mathrm{spH})$, a $\mathrm{pH}$-sensitive green fluorescent protein that allows optical discrimination between unfused and fused vesicles (Miesenböck et al., 1998; Sankaranarayanan and Ryan, 2000; Gandhi and Stevens, 2003). Simultaneously, we monitored the ability of vesicle to take up extracellularly added HEPES molecules and FM 4-64, a red fluorescent dye that stains membranes and the vesicle matrix (Angleson et al., 1999; Stenovec et al., 2004, 2005). Finally, elementary fusion pore properties were studied by electrophysiological membrane capacitance measurements (Zorec et al., 1991).

\section{Materials and Methods}

Cell preparation and transfection. Lactotroph-enriched cell cultures were prepared from adult male Wistar rat anterior pituitaries as described previously (Ben-Tabou et al., 1994). Cells were plated on glass coverslips coated with poly-L-lysine and maintained in high-glucose DMEM (Invitrogen, San Diego, CA) supplemented with $10 \%$ newborn calf serum and L-glutamine in an atmosphere of humidified air (92\%) and $\mathrm{CO}_{2}$ $(8 \%)$. One-day-old cultures were transfected with $\mathrm{spH}$ in a pCI neo vector (Promega, Madison, WI) using Lipofectamine Plus (Invitrogen) as described previously (Miesenböck et al., 1998). The spH plasmid construct was a gift from G. Miesenböck (Sloan-Kettering Institute, Memorial Sloan-Kettering Cancer Center, New York, NY). All experiments were performed at room temperature $2-4 \mathrm{~d}$ after transfection.

The animals were killed in accordance with the International Guiding Principles for Biomedical Research Involving Animals developed by the Council for International Organizations of Medical Sciences and the Directive on Conditions for Issue of License for Animal Experiments for Scientific Research Purposes (Official Gazette of the Republic of Slovenia 40/85 and 22/87).

Solutions. Standard saline solution was prepared consisting of (in $\mathrm{mm}$ ) $10 \mathrm{HEPES} / \mathrm{NaOH}, \mathrm{pH} 7.2,10$ D-glucose, $130 \mathrm{NaCl}, 8 \mathrm{CaCl}_{2}, 1 \mathrm{MgCl}_{2}$, and $5 \mathrm{KCl}$. Ammonium chloride solution, $\mathrm{pH}$ 7.2, was prepared by replacing $50 \mathrm{~mm} \mathrm{NaCl}$ in the standard saline solution with $50 \mathrm{~mm} \mathrm{NH}_{4} \mathrm{Cl}$. To prepare $100 \mathrm{~mm}$ HEPES solution, $\mathrm{pH}$ 7.2, we increased the HEPES in a standard saline solution from 10 to $100 \mathrm{~mm}$ and lowered the $\mathrm{NaCl}$ concentration to $85 \mathrm{~mm}$. A concentration of $100 \mathrm{~mm} \mathrm{KCl}$ solution was prepared by replacing $95 \mathrm{~mm} \mathrm{NaCl}$ in the standard saline solution with 95 mm KCl. All chemicals were from Sigma-Aldrich (St. Louis, MO).

Immunocytochemistry. Lactotrophs expressing $\mathrm{spH}$ were fixed with $4 \%$ paraformaldehyde and permeabilized with $0.1 \%$ Triton X-100; nonspecific sites were blocked with $3 \%$ bovine serum albumin and $10 \%$ goat serum. Prolactin was detected by incubating lactotrophs with rabbit antiprolactin polyclonal antibodies (1:80; Chemicon, Temecula, CA) in combination with secondary Alexa Fluor ${ }^{546}$-conjugated anti-rabbit IgG antibodies (1:500; Invitrogen). Before confocal microscopy, cells were treated with the Slow Fade Light Antifade kit (Invitrogen). Immunolabeled cells were analyzed with an inverted Zeiss (Jena, Germany) LSM 510 confocal microscope with an oil-immersion plan apochromatic objective [63×, 1.4 numerical aperture (NA)] using $488 \mathrm{~nm}$ Ar-ion and 543 $\mathrm{nm}$ He-Ne laser excitation. Emission spectra were acquired sequentially with a $505-530 \mathrm{~nm}$ bandpass emission filter $(\mathrm{spH})$ and a $560 \mathrm{~nm}$ longpass emission filter (Alexa Fluor ${ }^{546}$ ).

Colocalization of $\mathrm{spH}$ and Alexa Fluor ${ }^{546}$ fluorescence signals of immunolabeled prolactin was determined by analysis of TIFF files with a custom MATLAB program (Kreft et al., 2004) that counts red, green, and colocalized pixels. The threshold for colocalized pixel count was set at $20 \%$ of maximum green and red fluorescence intensity. Colocalization was expressed as the ratio of colocalized to green pixels (percentage).

Time-lapse confocal microscopy. Laser-scanning fluorescence images of lactotrophs were acquired with an inverted confocal microscope (Zeiss LSM 510). Coverslips with transfected cells were mounted in standard saline solution or $100 \mathrm{~mm}$ HEPES solution containing $4 \mu \mathrm{M}$ FM 4-64 (Invitrogen) in a perfusion-stimulation chamber on the microscope stage. For exposure to $\mathrm{NH}_{4} \mathrm{Cl}$, cells were perfused with the ammonium chloride solution containing $4 \mu \mathrm{M}$ FM 4-64. In stimulation experiments, cells were superfused with $100 \mathrm{~mm} \mathrm{KCl}$ solution $30 \mathrm{~s}$ after the start of recording. After excitation at $488 \mathrm{~nm}$, fluorescence emission was collected through a plan apochromatic objective $(63 \times, 1.4 \mathrm{NA})$ with a $505-$ $530 \mathrm{~nm}$ bandpass emission filter $(\mathrm{spH})$ and a $585 \mathrm{~nm}$ long-pass emission filter (FM 4-64). Time-lapse fluorescence images $(512 \times 512$ pixels $)$ were obtained every $\sim 0.5 \mathrm{~s}$ for up to $2 \mathrm{~min}$ ( $\sim 240$ frames). Each cell was monitored several times. The thickness of optical sections was $\sim 2 \mu \mathrm{m}$.

Electrophysiology. $C_{\mathrm{m}}$ was measured by using the cell-attached configuration with a dual-phase lock-in patch-clamp amplifier [sine-wave frequency $(f), 1591 \mathrm{~Hz} ; 111 \mathrm{mV}$ root mean square; SWAM IIC; Celica, Ljubljana, Slovenia]. All recordings were performed with fire-polished, thick-wall pipettes. The resistance of patch pipettes ranged from 2 to 5 $\mathrm{M} \Omega$; the pipette potential was held at $0 \mathrm{mV}$. The phase of the lock-in amplifier was adjusted to nullify the changes in the $R_{\mathrm{e}}$ part of the admittance signal in response to $10 \mathrm{fF}$ calibration steps in the $I_{\mathrm{m}}$ part of the signal as described previously (Zorec et al., 1991).

Time-dependent changes in $I_{\mathrm{m}}$ (proportional to $C_{\mathrm{m}}$ ) were recorded under basal conditions and during the cell $\mathrm{KCl}$ stimulation. The bath and the pipette contained standard saline solution. Stimulation solution (in mM: $10 \mathrm{HEPES} / \mathrm{NaOH}$, pH 7.2, 10 D-glucose, $5 \mathrm{NaCl}, 8 \mathrm{CaCl}_{2}, 1 \mathrm{MgCl}_{2}$, and $130 \mathrm{KCl}$ ) was added to the recording chamber as a bolus to reach the final concentration of $100 \mathrm{~mm} \mathrm{KCl}$.

For transient fusion events with projections between $R_{\mathrm{e}}$ and $I_{\mathrm{m}}, C_{\mathrm{v}}$ and $G_{\mathrm{p}}$ were calculated from the $I_{\mathrm{m}}$ and $R_{\mathrm{e}}$ portions of the admittance signals as reported previously (Lollike and Lindau, 1999): $C_{\mathrm{v}}=\left[\left(R_{\mathrm{e}}{ }^{2}+I_{\mathrm{m}}{ }^{2}\right) /\right.$ $\left.I_{\mathrm{m}}\right] / \omega$, where $\omega$ is the angular frequency $(\omega=2 \pi f)$ and $G_{\mathrm{p}}=\left(R_{\mathrm{e}}{ }^{2}+\right.$ $\left.I_{\mathrm{m}}{ }^{2}\right) / R_{\mathrm{e}}$. Fusion pore diameter was estimated with the equation $G_{\mathrm{p}}=$ $\left(\pi r^{2}\right) /(\rho \lambda)$, where $r$ is the fusion pore radius, $\rho$ is the resistivity of the saline $(100 \Omega \mathrm{cm})$, and $\lambda$ is the length of a gap junction channel $(15 \mathrm{~nm})$ (Spruce et al., 1990). Transient events were analyzed by using the cursor option in the software subroutine (CellAn; Celica) written for MATLAB (MathWorks, Natick, MA).

Image and data analysis. Cells were scanned by eye for an individual exocytotic event by rapidly replaying the movie ( $\sim 240$ frames) in forward and reverse directions. The onset of exocytosis was defined as the first frame showing a significant increase in $\mathrm{spH}$ fluorescence. A circular region of interest (ROI) 15 pixels in diameter was centered on the spot where the event occurred, and changes in the fluorescence intensities of spH and FM 4-64 were monitored over time. Single-exponential $\left[F=F_{0}\right.$ $+c \times \exp (-\mathrm{t} / \tau)]$ or double-exponential $\left[F=F_{0}+c_{1} \times \exp \left(-\mathrm{t} / \tau_{1}\right)+c_{2}\right.$ $\left.\times \exp \left(-\mathrm{t} / \tau_{2}\right)\right]$ decay functions were fitted to the diagrams with $\mathrm{spH}$ fluorescence changes using SigmaPlot (Systat Software, San Jose, CA). F is the fluorescence at time $t, F_{0}$ is the baseline fluorescence, $c$ is the fluorescence amplitude of $F_{(t=0)}-F_{0}, c_{1}$ and $c_{2}$ are the fluorescence amplitudes of individual exponential components of a doubleexponential function, and $\tau$ is the time constant of an individual exponential component. The goodness of the exponential fits was judged from the calculated coefficient of determination, $R^{2}$. The changes in spH and FM 4-64 fluorescence $\left(\Delta F=F-F_{0}\right)$ in diagrams were normalized to the initial fluorescence signal $\left(F_{0}\right), \Delta F / F_{0}$. The linear function fits $(y=a+b \times x)$ in scatter plot diagrams were obtained with SigmaPlot. Images were contrasted with linear interpolation and filtered with a Gaussian filter (radius of 0.5 pixels). Images of a single exocytotic vesicle (ROI) in Figures $1 b, 2,3$, and 5 were cropped $(45 \times 45$ pixels $)$ from the original image. Cropped images were resampled into $236 \times 236$ pixel images using bilinear interpolation. Values are reported as means \pm SEM. Statistical significance was evaluated by Student's $t$ test, unless stated otherwise.

\section{Results \\ $\mathrm{spH}$ is expressed in prolactin-containing vesicles in lactotrophs}

To study spontaneous single-vesicle fusion events in real time, we used lactotrophs transfected with $\mathrm{spH}$, a $\mathrm{pH}$-dependent protein 

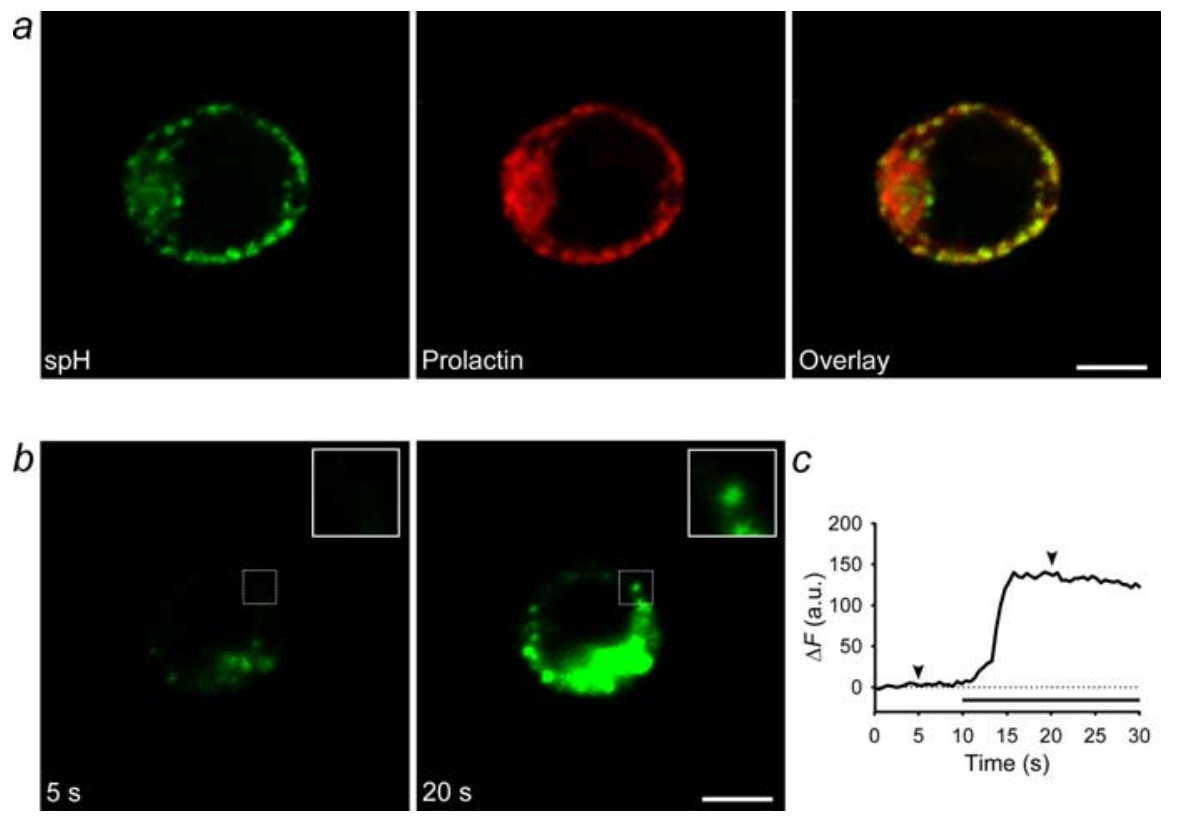

Figure 1. Functional expression of $\mathrm{spH}$ in prolactin-containing vesicles. $\boldsymbol{a}$, Colocalization of $\mathrm{spH}$ with prolactin in lactotrophs. Cells expressing spH were fixed and labeled first with anti-prolactin antibodies and then with Alexa Fluor ${ }^{546}$-conjugated secondary antibodies. In the overlay image, yellow indicates colocalization of green $(\mathrm{spH})$ and red (prolactin) fluorescence. $\boldsymbol{b}, \boldsymbol{c}$, Timedependent brightening of prolactin vesicle after application of $50 \mathrm{~mm} \mathrm{NH}_{4} \mathrm{Cl}$ solution. $\boldsymbol{b}$, Images of a lactotroph before (5s) and after $\left(20 \mathrm{~s}\right.$ ) exposure to $\mathrm{NH}_{4} \mathrm{Cl}$. The insets show a single prolactin vesicle. $c$, The time course of spH fluorescence intensity changes $(\Delta F)$ at the vesicle site (ROI) during exposure to $\mathrm{NH}_{4} \mathrm{Cl}$. The horizontal black bar indicates of exposure to $\mathrm{NH}_{4} \mathrm{Cl}$; arrowheads indicate the time points of image acquisition. a.u., Arbitrary units. Scale bars, $5 \mu \mathrm{m}$.

consisting of the vesicle membrane-targeted protein VAMP2 (synaptobrevin-2) with a $\mathrm{pH}$-sensitive enhanced green fluorescent protein (superecliptic pHluorin) fused to its luminal side (Miesenböck et al., 1998). At the acidic $\mathrm{pH}$ of resting vesicles, $\mathrm{spH}$ fluorescence is quenched by protons because of the $\mathrm{H}^{+}$-ATPase activity. After fusion with the plasma membrane, the vesicle interior becomes accessible from the extracellular environment (more alkaline $\mathrm{pH}$ ), allowing the protons to escape. The fluorescence intensity of $\mathrm{spH}$ increases rapidly and remains elevated until the pore closes and the vesicle is reacidified (Miesenböck et al., 1998).

To verify that $\mathrm{spH}$ localizes to prolactin vesicles, we immunostained transfected lactotrophs with anti-prolactin antibodies. The punctuate distribution of green $\mathrm{spH}$ fluorescence colocalized with red anti-prolactin fluorescence (Fig. 1a). The degree of colocalization was $82 \pm 2 \%$ (mean \pm SEM of 74 images from six cells), indicating that $\mathrm{spH}$ was predominantly targeted to the prolactin-containing vesicles.

To test whether $\mathrm{spH}$ expressed in prolactin-containing vesicles of lactotrophs can sense $\mathrm{pH}$ changes, we treated $\mathrm{spH}$ expressing cells with saline solution containing $\mathrm{NH}_{4} \mathrm{Cl}(50 \mathrm{~mm})$, which neutralizes the $\mathrm{pH}$ of all cellular organelles (Roos and Boron, 1981). $\mathrm{NH}_{4} \mathrm{Cl}$ induced a rapid increase in $\mathrm{spH}$ fluorescence (Fig. 1b,c), indicating $\mathrm{pH}$ sensitivity, as in vesicles of hippocampal neurons (Sankaranarayanan and Ryan, 2000), PC-12 cells (Taraska et al., 2003), and pancreatic MIN6 $\beta$-cells (OharaImaizumi et al., 2002; Tsuboi and Rutter, 2003).

\section{Spontaneous exocytotic vesicles differ in ability to load FM 4-64}

To observe spontaneous exocytotic events, we monitored changes in $\mathrm{spH}$ fluorescence intensity of apparently docked vesicles after extracellular addition of FM 4-64, which strongly labels prolactin-containing vesicles (Angleson et al., 1999; Stenovec et al., 2004, 2005). Spontaneous exocytotic events, appearing as puncta with an abrupt increase in $\mathrm{spH}$ and/or FM 4-64 fluorescence intensity, were observed in $\sim 25 \%$ of lactotrophs (166 cells studied; total recording time $99,600 \mathrm{~s}$ ). In all, 64 vesicles ( 36 in standard saline, 28 in $100 \mathrm{~mm}$ HEPES solution) showed a spontaneous, rapid increase in $\mathrm{spH}$ fluorescence. Analysis of ROIs centered on the fusion sites revealed that the average time required for a $20-80 \%$ increase in $\mathrm{spH}$ fluorescence (rise time $_{20-80 \%}$ ) was $<0.5$ s (limited by data acquisition rate), indicating an efflux of protons through a newly formed fusion pore. After fluorescence intensity peaked in the 36 vesicles in standard saline, the green fluorescent puncta either dimmed ( $n=23 ; 64 \%)$, implying reacidification after closure of the fusion pore, or remained visible throughout the experiment ( $n=13 ; 36 \%$ ), indicating that the vesicle lumen remained effectively in diffusional contact with the extracellular space via the fusion pore. In 11 vesicles, the $\mathrm{spH}$ fluorescence signal was already elevated at the beginning of recording, indicating an open fusion pore. During the recording, the $\mathrm{spH}$ signal decayed in a few seconds as if the fusion pore had resealed and the vesicle had been reacidified (Gandhi and Stevens, 2003). These vesicles were not included in the analysis because the onset of exocytosis was not discernible.

In 17 (47\%) of the $36 \mathrm{spH}$-positive spontaneous fusion events, the appearance of green fluorescent puncta was paralleled by red fluorescent labeling from FM 4-64 entering the prolactin vesicle (Stenovec et al., 2004), likely through the same fusion pore as the exiting protons. Labeling with FM 4-64 revealed two types of spontaneous exocytotic events, type I and type II events, that could be further subdivided by the transience or persistence of $\mathrm{spH}$ fluorescence. Both types of events could be observed in the same cell.

\section{Spontaneous type I exocytotic events}

In type I exocytotic events $(n=19 ; 53 \%)$, FM 4-64 fluorescence did not increase with the spH signal (Fig. 2, bottom), likely because the fusion pore was too narrow for entry of the dye into the vesicle lumen. In 12 vesicles (Fig. $2 a$ ), spH fluorescence declined rapidly after peaking (half time, $1.3 \pm 0.2 \mathrm{~s}$ ). Although, vesicle movement cannot be ruled out completely, the decay phase of type I transient events most likely represents endocytosis and reacidification of the vesicle (Sankaranayanan and Ryan, 2000; Gandhi and Stevens, 2003; Atluri and Ryan, 2006). In seven vesicles (Fig. $2 b)$, spH fluorescence persisted at the peak level $(n=3)$ or declined slowly (half time, $>100 \mathrm{~s} ; n=4$ ). In three vesicles undergoing transient exocytosis, the fusion pore appeared to reopen several times, as judged by the multiple peaks (some with complex shapes) (Fig. $2 a$, insets) and rapid declines of spH fluorescence, as observed in vesicles of hippocampal neurons (Miesenböck et al., 1998). Although the declines in spH fluorescence differed in transient and persistent type I events $(p<$ 0.001 , three persistent type I events were excluded because $\mathrm{spH}$ 
fluorescence did not decrease during the recording), the mean peak amplitudes were similar ( $134 \pm 26 \%$ vs $177 \pm 58 \%$; $n=12$ and 7 , respectively; $p=0.43$ ).

\section{Spontaneous type II exocytotic events}

In spontaneous type II exocytotic events ( $n=17 ; 47 \%$ ), spH and FM 4-64 fluorescence increased in parallel (Fig. 3, bottom), indicating that the fusion pore was wide enough for FM 4-64 to enter the vesicles. In 11 vesicles, $\mathrm{spH}$ fluorescence was transient (Fig. 3a). In six vesicles, it was persistent, either with no decline $(n=2)$ or with a slow decay (half time, $>100 \mathrm{~s}$; $n=4$ ) (Fig. 3b). As with type I events, the mean peak amplitudes of $\mathrm{spH}$ fluorescence were similar $(291 \pm 57 \%$ in transient events vs $267 \pm 56 \%$ in persistent events; $n=11$ and 6 , respectively; $p=$ $0.9)$, but the decay kinetics differed significantly $(p<0.001$; two persistent type II events were excluded because $\mathrm{spH}$ fluorescence did not decrease during the recording).

The peak amplitudes of FM 4-64 fluorescence were similar in transient and persistent type II events ( $168 \pm 29 \%$ vs $161 \pm$ $98 \% ; n=11$ and 6 , respectively; $p=0.66$ ). However, the time required to reach the peak amplitude differed significantly as judged by the average rise time $_{20-80 \%}$, which was fourfold faster in transient than persistent type II events ( $1.6 \pm 0.3$ vs $5.7 \pm$ $1.2 \mathrm{~s} ; n=11$ and 6 , respectively; $p<$ $0.001)$. The slower time course may reflect a narrow fusion pore (Richards et al., 2005) or a reduction in the effective "open time" because of fusion pore pulsing (Stenovec et al., 2004).

Analysis of $\mathrm{spH}$ fluorescence decay showed that it was nine times faster for transient type I than transient type II events (average half time, $1.3 \pm 0.2$ vs $11.7 \pm 1.9 \mathrm{~s} ; n=12$ and 11 , respectively; $p<0.001)$. Transient type I events were best fitted by a single-exponential function with an average time constant $(\tau)$ of $1.2 \pm 0.2 \mathrm{~s}$. Transient type II events, however, were best fitted by a double-exponential function with an average fast component $\left(\tau_{1}\right)$ of $1.9 \pm 0.6 \mathrm{~s}$ and an average slow component $\left(\tau_{2}\right)$ of $29.6 \pm$ $5.3 \mathrm{~s}$. Differences in the $\mathrm{spH}$ fluorescence intensity decline likely indicate distinct reacidification kinetics in the transient type I and transient type II events. Spontaneous transient type I and type II events differed also in the amplitude of $\mathrm{spH}$ fluorescence. The mean peak amplitude of $\mathrm{spH}$ fluorescence was twofold higher in type II events ( $134 \pm 26 \%$ vs $291 \pm 57 \% ; n=12$ and 11 , respectively; $p<0.02)$, which is consistent with compound fusion (Pelkmans and Zerial, 2005), as commonly observed in stimulated lactotrophs (Angleson et al., 1999; Cochilla et al., 2000).

Increased $\mathrm{pH}$ buffer concentration slows reacidification only in vesicles that load FM 4-64

The time course of the decline in $\mathrm{spH}$ fluorescence intensity reflects the time required for retrieval and reacidification of the vesicle (Miesenböck et al., 1998). Therefore, if changes in $\mathrm{spH}$ $b$

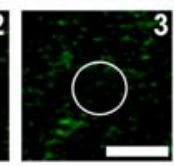

Transient
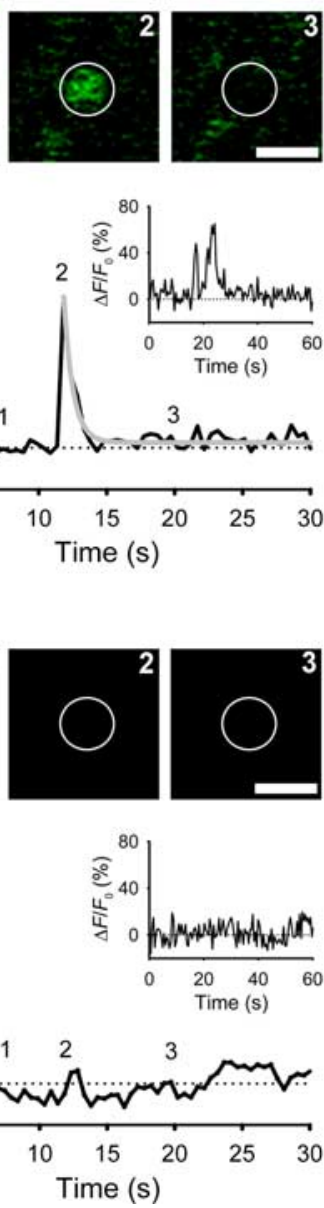

Persistent

$\mathrm{spH}$
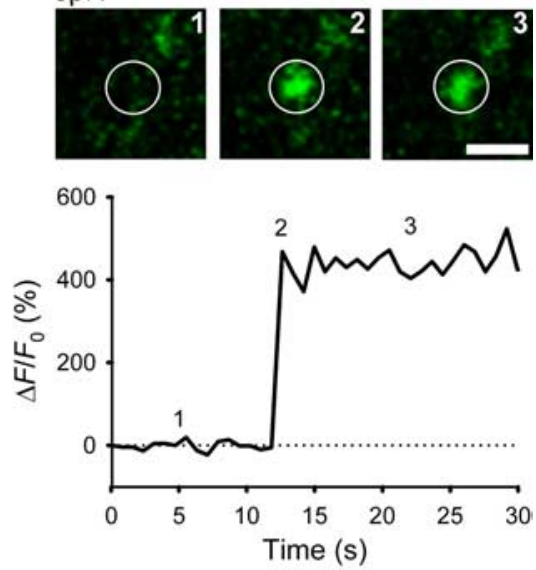

FM 4-64
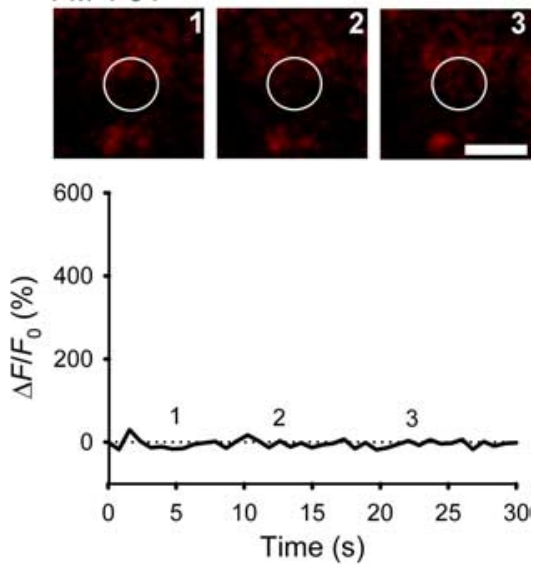

Figure 2. Spontaneous type l exocytotic events. Sequential images of a single vesicle and changes in spH and FM 4-64 fluorescence at the vesicle site are shown. Fluorescence signals are plotted as the change in fluorescence $(\Delta F)$ normalized to the initial luorescence $\left(F_{0}\right)$ in arbitrary units. $\boldsymbol{a}, \boldsymbol{b}$, Exocytosis resulted in a rapid increase in spH fluorescence, followed by a rapid singleexponential decline (gray line) with $\tau$ of $0.7 \mathrm{~s}(\boldsymbol{a})$ or a persistent elevation $(\boldsymbol{b})$. Insets in $\boldsymbol{a}$ show a repetitive type l exocytotic event. Numbers on plots correspond to times when images were recorded. White circles indicate ROls. Scale bars, $1 \mu \mathrm{m}$.

fluorescence are associated with exposure of the $\mathrm{pH}$-sensitive moiety of the $\mathrm{spH}$ fusion protein to the extracellular space, changes in $\mathrm{pH}$ buffering capacity should affect the time course of recorded spH fluorescence signals (Gandhi and Stevens, 2003).

Types I and II spontaneous exocytotic events in resting lactotrophs were defined by differences in the permeation of FM 4-64 dye $\left(\mathrm{M}_{\mathrm{w}}=608 \mathrm{~g} / \mathrm{mol}\right)$ across the fusion pore (Figs. 2, 3). To determine whether the fusion pores of prolactin-containing vesicles undergoing spontaneous exocytosis also differ in the permeation of the $40 \%$ smaller $\mathrm{pH}$ buffer molecule HEPES $\left(\mathrm{M}_{\mathrm{w}}=238\right.$ $\mathrm{g} / \mathrm{mol}$ ), we raised its concentration in the bathing solution from 10 to $100 \mathrm{~mm}$. We expected that the addition of HEPES would slow the decline in $\mathrm{spH}$ fluorescence (during reacidification) only in the exocytotic vesicles with fusion pores wide enough for HEPES to enter the vesicular lumen (Gandhi and Stevens, 2003).

In type I events $(n=14)$, the average decay half time of $\mathrm{spH}$ fluorescence in cells exposed to $100 \mathrm{~mm}$ HEPES did not differ from that in cells exposed to $10 \mathrm{mM}$ HEPES (Table 1, Fig. 4a). Moreover, the proportion of transient and persistent type I events was similar under both conditions (Fisher's exact test, $p=0.72$ ). Thus, HEPES did not slow the reacidification of vesicles undergoing type I exocytosis. In type II events $(n=14)$, however, the proportion of persistent events was significantly higher than at 10 
a
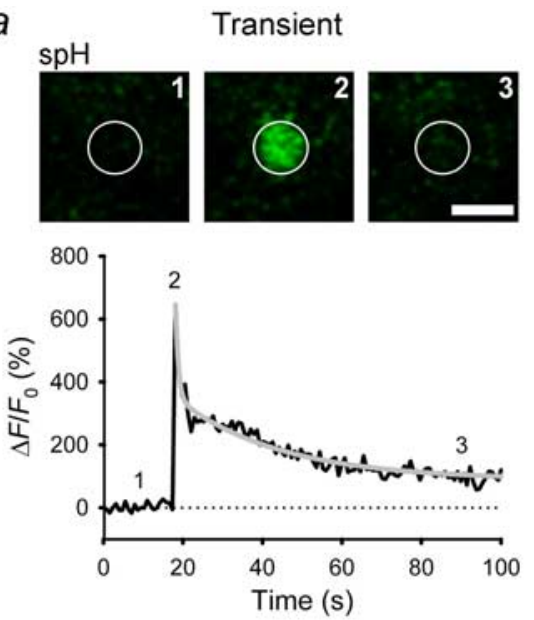

FM 4-64
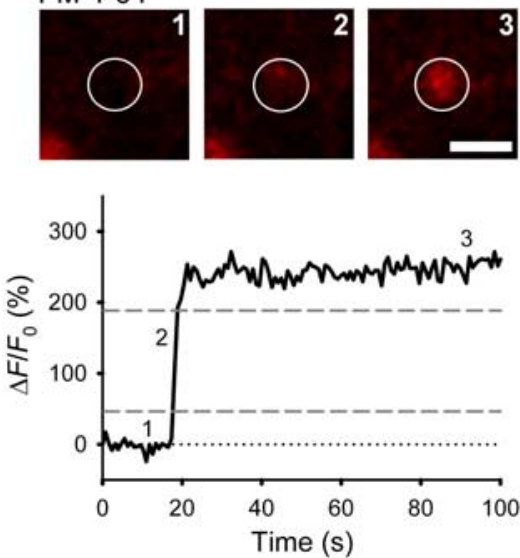

$b$
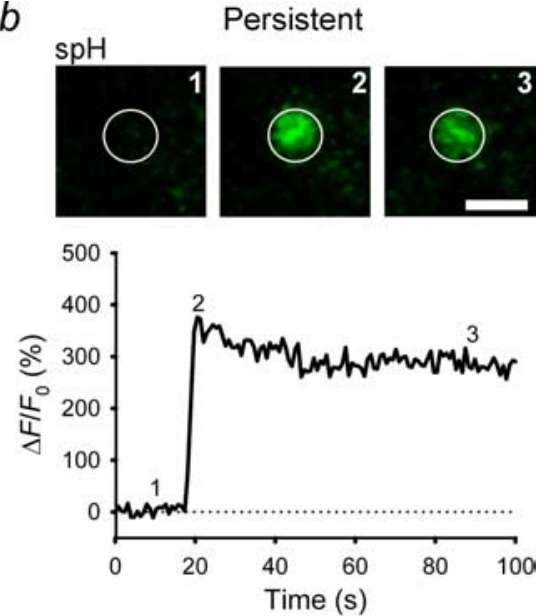

FM 4-64
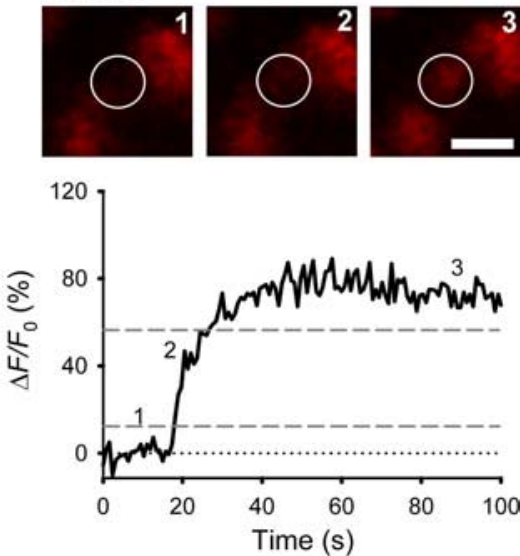

Figure 3. Spontaneous type II exocytotic events. Sequential images of a single vesicle and changes in spH and FM 4-64 fluorescence, plotted as in Figure 2, at the vesicle site are shown. $\boldsymbol{a}, \boldsymbol{b}$, Exocytosis resulted in a rapid increase in spH fluorescence, followed by a double-exponential decay in spH fluorescence (gray line) with a fast component $\left(\tau_{1}\right)$ of $0.7 \mathrm{~s}$ and a slow component $\left(\tau_{2}\right)$ of $24.6 \mathrm{~s}(\boldsymbol{a})$ or persistent elevation $(\boldsymbol{b})$. Dashed lines indicate levels of fluorescence signal used to calculate the time needed for a $20-80 \%$ increase in FM 4-64 fluorescence (rise time ${ }_{\mathrm{FM} 4-64}$ ). Numbers on the plots correspond to times when images were recorded. White circles indicate ROls. Scale bars, $1 \mu \mathrm{m}$.

Table 1. Influence of pH buffer capacity on decay time $\left(t_{1 / 2}\right)$ of spH fluorescence in spontaneous exocytotic events

\begin{tabular}{|c|c|c|c|c|}
\hline \multirow[b]{2}{*}{ Events } & \multicolumn{2}{|l|}{$10 \mathrm{~mm}$ HEPES } & \multicolumn{2}{|l|}{100 mm HEPES } \\
\hline & Average $t_{1 / 2}(\mathrm{~s})$ & Percentage & Average $t_{1 / 2}(\mathrm{~s})$ & Percentage \\
\hline \multicolumn{5}{|l|}{ Type I } \\
\hline Transient & $1.3 \pm 0.2(n=12)$ & 63 & $1.6 \pm 0.2(n=10)$ & 71 \\
\hline Persistent & $>100(n=7)$ & 37 & $>100(n=4)$ & 29 \\
\hline \multicolumn{5}{|l|}{ Type II } \\
\hline Transient & $11.7 \pm 1.9(n=11)$ & 65 & $8.4(n=1)$ & 7 \\
\hline Persistent & $>100(n=6)$ & 35 & $>100(n=13)$ & 93 \\
\hline
\end{tabular}

Note the changes in percentages of transient and persistent type Il events between 10 and $100 \mathrm{~mm}$ buffer conditions (Fisher's exact test, $p<0.01$ ).

mM HEPES (93\% vs 35\%; Fisher's exact test, $p<0.01$ ). At 100 mM HEPES, 13 of 14 type II events were persistent, consistent with slowed reacidification attributable to increased influx of HEPES into the vesicular lumen through the fusion pore. In the transient event, the decay half time was $8.4 \mathrm{~s}$, similar to that recorded most frequently in cells exposed to $10 \mathrm{mM}$ HEPES (Table 1, Fig. $4 a$ ).

Stimulated vesicles have greater ability to load FM 4-64 than spontaneous ones

In chromaffin cells, higher levels of stimulation are thought to lead to fusion pore expansion (Elhamdani et al., 2001; Fulop et al., 2005). To determine whether stimulation shifts the mode of exocytosis from type I to type II, with a larger FM 4-64- and HEPES-permeable pore, we stimulated lactotrophs with $100 \mathrm{~mm} \mathrm{KCl}$ immediately after observing spontaneous exocytotic events (three cells). After stimulation, no changes in spH or FM 4-64 fluorescence were observed at the sites of spontaneous persistent type I and type II exocytosis. Furthermore, stimulation failed to trigger exocytosis at sites of previous spontaneous transient exocytotic events, as if the vesicles were fully endocytosed at rest and became insensitive to stimulation. However, stimulation triggered exocytosis of new vesicles $(n=28)$. As in spontaneous events, the $\mathrm{spH}$ fluorescence increase was $<0.5 \mathrm{~s}$ in stimulated events, indicating an efflux of protons through a newly formed fusion pore. In 20 (71\%) of 28 new vesicles entering exocytosis, the FM 4-64 fluorescence increased together with the $\mathrm{spH}$ fluorescence signal (type II events) (Fig. 5b), indicating that the fusion pore was wide enough for FM 4-64 to enter the vesicle. In 8 (29\%) stimulated vesicles, the FM 4-64 did not enter the vesicle lumen (type I events) (Fig. 5a). Thus, the markedly higher proportion of type II events in stimulated than in unstimulated cells (71\% vs $47 \%$ ) (Table 2) likely indicates that stimulation by $100 \mathrm{~mm} \mathrm{KCl}$ triggers exocytotic events with larger fusion pore diameters compared with spontaneous events.

Transient fusion pore opening is the predominant mode of exocytosis in resting and stimulated lactotrophs In chromaffin cells, stimulation is thought to shift the mode of exocytosis from transient (kiss-and-run) to persistent (full fusion) (Fulop et al., 2005; Elhamdani et al., 2006). By monitoring $\mathrm{spH}$ fluorescence, both type I and type II events were classified as persistent or transient. However, the majority of stimulated events were persistent $(n=26)$; only two events were transient (Table 2). Although persistent events likely mirror full fusion of vesicles, one cannot exclude the possibility that persistent events represent kiss-and-run exocytosis with rapid fusion pore flickers. To further test these possibilities, we performed electrophysiological experiments to monitor the fusion pore properties directly.

The cell-attached patch-clamp configuration was used to monitor discrete steps in membrane capacitance $\left(C_{\mathrm{m}}\right.$; proportional to the imaginary part of admittance, $\left.I_{\mathrm{m}}\right)$, where increases (on-steps) correspond to single exocytotic events (Neher and Marty, 1982). Discrete steps in $C_{\mathrm{m}}$ (total $\left.n=2422\right)$ were revealed in 7 of 18 patches before $(n=209)$ and after stimulation $(n=$ 2213) during a recording time of 4708 s. Figure $6 a$ shows a representative experiment in which spontaneous discrete steps in 
a
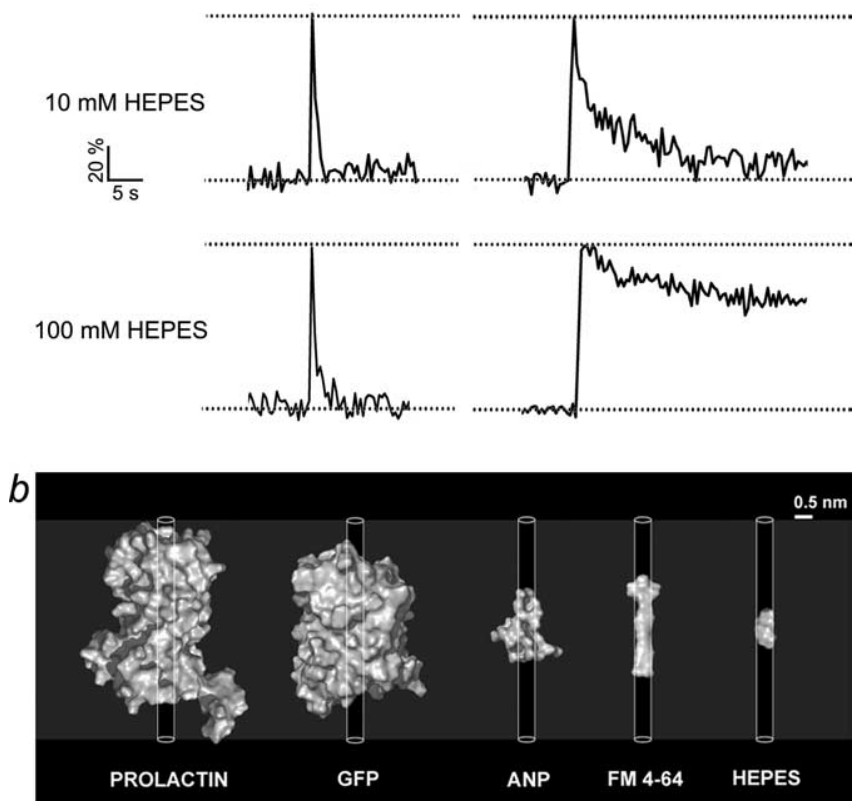

Figure 4. Addition of small HEPES molecules to the bath slows reacidification only in vesicles that load FM 4-64. $\boldsymbol{a}$, Representative spontaneous type I and type Il exocytotic events in 10 and $100 \mathrm{~mm}$ HEPES bath solution. $\mathrm{spH}$ fluorescence intensity was normalized as $\left(F-F_{0}\right) /\left(F_{\max }-\right.$ $F_{0}$ ), where $F$ is the fluorescence at any given time point. Dotted lines indicate minimal and maximal levels of $\mathrm{spH}$ fluorescence signal. Note the slower spH fluorescence decline of type II events in the $100 \mathrm{~mm}$ HEPES bath solution. $\boldsymbol{b}$, Surface models of prolactin, green fluorescent protein (GFP), atrial natriuretic peptide (ANP), FM 4-64, and HEPES. The three-dimensional (3D) structure data for prolactin, GFP, and ANP were from Brookhaven Protein Data Bank (PDB). The 3D structure data for HEPES were from the National Cancer Institute database. The 3D structure of FM 4-64 was predicted from the two-dimensional structure using MDL ISIS/Draw (version 2.5). The surface models of molecules were generated with a Pymol Molecular Graphics System. The cylinders indicate the dimension of a fusion pore with a diameter of $0.5 \mathrm{~nm}$ and a length equal to the membrane thickness. See Table 3 for dimension.

$C_{\mathrm{m}}$, recorded in the same patch of membrane, are displayed on the left before stimulation and on the right after stimulation with $100 \mathrm{~mm} \mathrm{KCl}$. Along with the time-dependent changes in $C_{\mathrm{m}}$, the time-dependent changes of the real part of admittance signal $\left(R_{\mathrm{e}}\right)$ are shown above. Under both conditions, all but 10 on-steps in $C_{\mathrm{m}}(n=2412)$ were followed by discrete off-steps within a few seconds, representing a transient fusion event (Neher and Marty, 1982), which likely derives from reversible fusion of a single vesicle with the plasma membrane. The mean peak amplitude of spontaneous and stimulated transient events from the same recording was similar before and after stimulation $[0.57 \pm 0.05$ $(n=25)$ vs $0.57 \pm 0.04 \mathrm{fF}(n=331)$ ] (Fig. 6b). Moreover, the coefficient of correlation between the on-step and subsequent off-step was close to 1 (Fig. 6c, top) (Neher and Marty, 1982), indicating that discrete steps in $C_{\mathrm{m}}$ report repetitive fusion events of the same vesicle before and after stimulation. A similar behavior was observed in all patches with amplitudes ranging from 0.3 to $10 \mathrm{fF}$ in particular recordings.

The occurrence of transient events in the $I_{\mathrm{m}}$ signal increased significantly in all patches after stimulation from $0.15 \pm 0.02$ events/s $(n=207)$ to $0.67 \pm 0.07$ events/s $(n=2,205 ; p<0.01)$ (for a representative experiment, see Fig. $6 c$, bottom). Nonreversing steps ( $0.4 \%$ of all events), representing full vesicle fusion (Neher and Marty, 1982), occurred with practically the same low incidence before and after stimulation $(0.0016 \pm 0.0011$ vs $0.0024 \pm 0.0015$ events/s; $p=0.57)$. These results indicate that persistent events in an imaging experiment (Figs. $2 b, 3 b, 5$ ) most likely consist of fast repetitive fusion pore flickers (Fig. 6a) (Stenovec et al., 2004) rather than full fusion.

\section{Stimulation increases fusion pore dwell time and pore conductance}

Fluorescence studies revealed that stimulated vesicles have a greater ability to load FM 4-64 than spontaneous exocytotic vesicles (Table 2). This is likely because of the increased occurrence of transient, flickering events (Fig. $6 c$, bottom). However, it may also be attributable to a longer fusion pore dwell time or a larger pore diameter.

Indeed, the average dwell time of transient fusion events was longer after stimulation $[130 \pm 20 \mathrm{~ms}(n=207)$ vs $220 \pm 10 \mathrm{~ms}$ $(n=2,205) ; p<0.01]$. Figure $6 d$ shows the histogram of transient fusion pore dwell times for a representative experiment, which was, at rest, best fitted by a Gaussian with a mean of $62 \pm$ $2 \mathrm{~ms}(n=25)$, as shown previously (Stenovec et al., 2004). However, in contrast to spontaneous fusion pore openings, the stimulated events were best fitted by an exponential function with a time constant of $287 \pm 0.02 \mathrm{~ms}$ (Fig. $6 d)(n=331 ; p<0.05)$.

To determine the fusion pore conductance $\left(G_{\mathrm{p}}\right)$, the $R_{\mathrm{e}}$ was monitored for cross talk with the discrete transient increase in the $I_{\mathrm{m}}$ (see Materials and Methods) (Lollike and Lindau, 1999). In five (71\%) of seven patches, the $G_{\mathrm{p}}$ of transient fusion pore events could be determined. Of 2412 transient fusion events, $94(4 \%)$ in the $I_{\mathrm{m}}$ trace exhibited cross talk with the $R_{\mathrm{e}}$ trace. However, these events were more frequent under resting than under stimulated conditions ( $25 \%$ vs $2 \%$ ). At rest, the $G_{\mathrm{p}}$ ranged from 8 to $200 \mathrm{pS}$ (mean, $53 \pm 9 \mathrm{pS} ; n=51$ ). These values correspond to fusion pore diameters of $0.4-2.0 \mathrm{~nm}$ (see Materials and Methods) (Spruce et al., 1990). However, the average conductance of relatively fewer stimulated fusion events with measurable $G_{\mathrm{p}}$ was significantly larger than that of resting events $(81 \pm 15 \mathrm{pS} ; n=43$; $p<0.05$ ) with a maximum of $530 \mathrm{pS}$, indicating that the diameter of fusion pore in the majority of stimulated events is $>3.2 \mathrm{~nm}$ $(n=2162 ; 98 \%)$ (for data from a single patch, see Fig. $6 e$, top). $G_{\mathrm{p}}$ values are comparable to those estimated in other electrophysiological studies (Lindau and Almers, 1995; Klyachko and Jackson, 2002; He et al., 2006).

Interestingly, although the number of transient fusion events increased after stimulation, the fraction of events exhibiting discernible cross talk between the $I_{\mathrm{m}}$ and $R_{\mathrm{e}}$ parts of the admittance signals, allowing the estimation of $G_{\mathrm{p}}$, was significantly reduced from $2.7 \pm 1.0 \% / \mathrm{s}(n=25)$ to $0.6 \pm 0.1 \% / \mathrm{s}(n=331)$ after stimulation (Fig. 6e, bottom) $(p<0.05)$. These results support the idea that the fusion pore properties are altered by stimulation: dwell time increases, whereas the narrow fusion pore widens upon stimulation.

\section{Discussion}

Spontaneous release of vesicle content in neuroendocrine cells is slower than stimulated release, likely because of the rapid repetitive transient fusion pore openings (Stenovec et al., 2004). In this study, we tested the hypothesis that the slow spontaneous release of peptides may also reflect a relatively narrow fusion pore opening.

\section{Two modes of permeation through spontaneously formed fusion pores}

To monitor the permeation properties of spontaneously forming fusion pores, we used rat pituitary lactotrophs expressing a $\mathrm{pH}-$ sensitive vesicular marker, spH (Miesenböck et al., 1998). This marker was predominantly expressed in prolactin-containing 
a
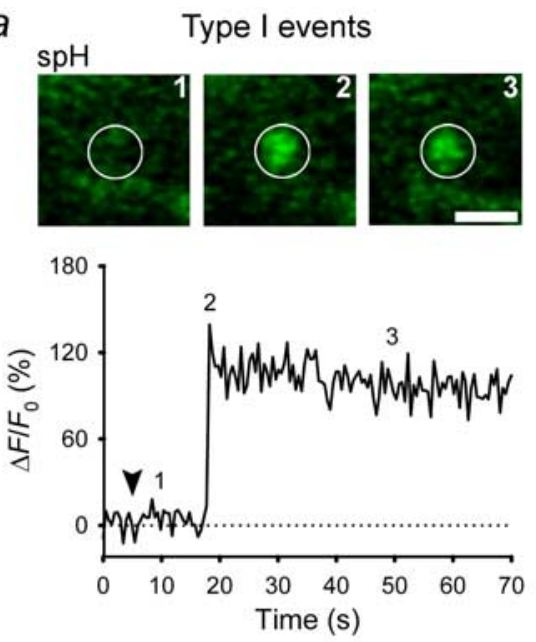

FM 4-64
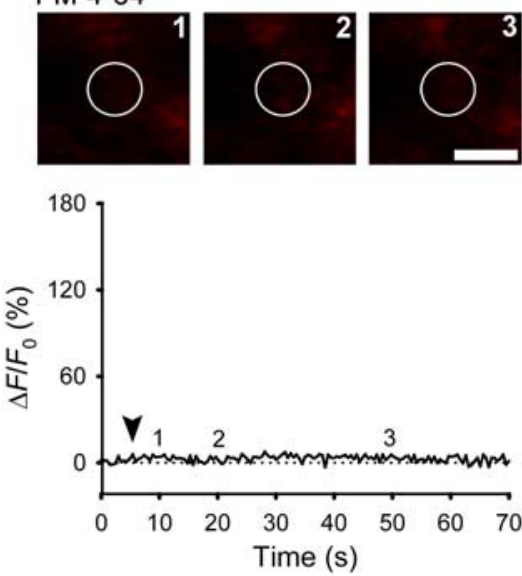

$b$
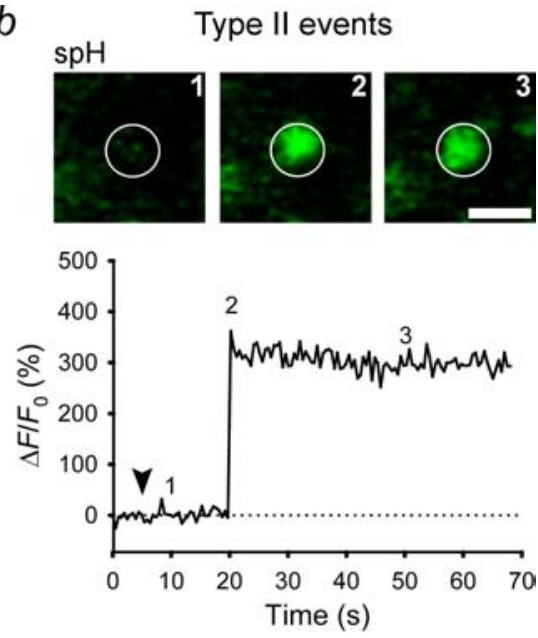

FM 4-64
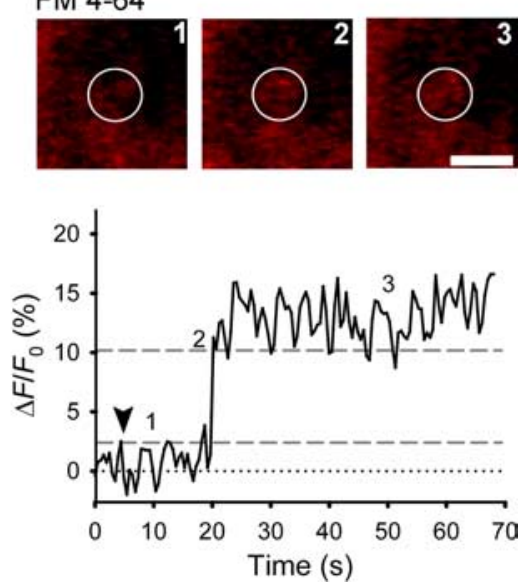

Figure 5. Stimulation of lactotrophs expressing spH. $\boldsymbol{a}, \boldsymbol{b}$, Representative sequential images of a single vesicle and changes in spH and FM 4-64 fluorescence at the vesicle site after stimulation with $100 \mathrm{~mm} \mathrm{KCl}$ solution are shown. The fluorescence signals are plotted as the change in fluorescence $(\Delta F)$ normalized to the initial fluorescence $\left(F_{0}\right)$ in arbitrary units. Exocytosis resulted in a rapid increase in spH fluorescence, followed by a persistent elevation. Dashed lines in $\boldsymbol{b}$ indicate levels of fluorescence signal used to calculate the time needed for a $20-80 \%$ increase in FM 4-64 fluorescence (rise time ${ }_{\mathrm{FM} 4-64}$ ). Numbers on the plots correspond to times when images were recorded. Arrowheads indicate the onset of stimulation. White circles indicate ROls. Scale bars, $1 \mu \mathrm{m}$.

Table 2. Stimulation with $100 \mathrm{~mm} \mathrm{KCl}$ changes the proportion of type I and type II events

\begin{tabular}{llc}
\hline Events & $\begin{array}{l}\text { Percentages of all spontaneous } \\
\text { events }\end{array}$ & $\begin{array}{l}\text { Percentages of all stimulated } \\
\text { events }\end{array}$ \\
\hline Type I & $\mathbf{5 3 ( n = 1 9 )}$ & $\mathbf{2 9 ( n = 8 )}$ \\
Transient & $63(n=12)$ & $0(n=0)$ \\
Persistent & $37(n=7)$ & $100(n=8)$ \\
Type II & $\mathbf{4 7 ( n = 1 7 )}$ & $\mathbf{7 1 ( n = 2 0 )}$ \\
Transient & $65(n=11)$ & $10(n=2)$ \\
Persistent & $35(n=6)$ & $90(n=18)$ \\
\hline
\end{tabular}

vesicles, and stimulation with ammonium chloride resulted in vesicle brightening, because the $\mathrm{pH}$ neutralization of the vesicle lumen relieved the proton quenching of $\mathrm{spH}$ fluorescence (Fig. 1). Simultaneous monitoring of exocytosis by a second fusion marker, extracellularly added FM 4-64 styryl dye (Stenovec et al., 2004, 2005), demonstrated two types of spontaneous exocytotic events (Figs. 2, 3). In 53\% of these events (type I), FM 4-64 was unable to enter the lumen of spH-positive vesicles after fusion (Fig. 2). In type II events, the dye entered the vesicular lumen, as indicated by the increase in red fluorescence (Fig. 3).
The fusion pore opens to subnanometer diameter in resting cells

For vesicular cargo release, the fusion pore must be large enough to allow the passage of the cargo. The difference in permeability to FM 4-64 we observed suggests that the fusion pore diameters are smaller in type I events than in type II events. In type I events, FM 4-64 molecules could not enter the vesicle, and increased concentrations of HEPES molecules, which are $40 \%$ smaller (238 vs $608 \mathrm{~g} / \mathrm{mol}$ ), did not slow the rapid decay of $\mathrm{spH}$ fluorescence (Table 1), suggesting that HEPES molecules were unable to pass the fusion pore. Based on the XYZ dimensions of molecules passing through the fusion pore (Fig. $4 b$, Table 3 ), we estimate that, in spontaneous type I events, the fusion pore is no larger than $\sim 0.5 \mathrm{~nm}$ (Fig. $4 b$, molecular dimension of HEPES) and may be even smaller. Under these conditions, it is unlikely that prolactin molecules can exit the vesicle lumen (Fig. 4b). In spontaneous type II exocytotic events, however, the fusion pore appeared to be wider, allowing the passage of molecules as large as $0.9 \mathrm{~nm}$ in diameter (FM 4-64) and perhaps much larger peptide hormones as well, such as atrial natriuretic peptide and prolactin (Stenovec at al, 2004) (Fig. 4b).

The fusion pore permeability to FM 4-64 and HEPES in type II events is in agreement with previous measurements of loading of FM dyes, horseradish peroxidase $\left(M_{\mathrm{w}}=40,000 \mathrm{~g} / \mathrm{mol}\right)$, and antibodies $\left(\mathrm{M}_{\mathrm{w}}=150,000 \mathrm{~g} / \mathrm{mol}\right)$ into spontaneously endocytosing synaptic vesicles (Malgaroli et al., 1995; Ryan et al., 1997; Sara et al., 2005). However, by using the $\mathrm{spH}$ construct, we were also able to see exocytotic events with fusion pore diameters smaller than the molecular dimensions of these molecules (type I events).

Cargo release from a vesicle depends not only on the fusion pore size but also on the dwell time of the open fusion pore (Stevens and Williams, 2000; Graham et al., 2002). Both HEPES and FM 4-64 are small molecules that diffuse a distance of $\sim 5 \mathrm{~nm}$ (membrane thickness) faster than $10^{-3} \mathrm{~ms}$, as estimated with the following equation: $t=x^{2} / D$, where $t$ is the time, $D$ is the diffusion coefficient of sucrose $\left(D=5.23 \times 10^{-7} \mathrm{~cm}^{2} / \mathrm{s} ; \mathrm{M}_{\mathrm{w}}=342\right.$ $\mathrm{g} / \mathrm{mol}$ ), and $x$ is the membrane thickness (Weiss, 1996). Because the average dwell time of a fusion pore at rest is $\sim 50 \mathrm{~ms}$ (Fig. 6) (Sun et al., 2002; Stenovec et al., 2004), it is most likely that the diameter of the fusion pore is the only limiting factor preventing the permeation of HEPES and FM 4-64 molecules in type I responses (Fig. 2, Table 1).

Transient and persistent fusion events reveal distinct mechanisms of spontaneous vesicle retrieval

In both types of spontaneous events, $\mathrm{spH}$ fluorescence was either transient or persistent (Figs. 2, 3, top). We did not observe lateral diffusion of $\mathrm{spH}$ from the site of exocytosis into the plasma membrane (data not shown) (Tsuboi and Rutter, 2003). Therefore, in 
both subtypes of fusion events, it is likely that vesicle exocytosis occurred in a nonfull-collapse manner (Taraska et al., 2003; Thorn and Parker, 2005).

In transient events, $\mathrm{spH}$ fluorescence peaked and rapidly declined, suggesting that the fusion pore closed shortly after opening, similar to the kiss-and-run exocytosis observed in other systems (Gandhi and Stevens, 2003; Tsuboi and Rutter, 2003). Because $65 \%$ of all spontaneous exocytotic fusion events were transient, the kiss-and-run mode seems to be the predominant form of vesicle exocytosis in resting lactotrophs (Figs. $2 a, 3 a$ ). Some of the transient events ( $8 \%$ ) occurred repeatedly (Fig. 2a, inset) as reported previously (Miesenböck et al., 1998), presumably because of fusion pore pulsing as observed in capacitance studies (Stenovec et al., 2004).

In $35 \%$ of all events, spH fluorescence peaked and was persistently elevated for at least $100 \mathrm{~s}$ (Figs. 2b, 3b), indicating that the fusion pore remained open, allowing continuous exposure of the vesicular lumen to the extracellular solution because of a long fusion pore lifetime, as in stimulated vesicles (Ohara-Imaizumi et al., 2002; Gandhi and Stevens, 2003; Perrais et al., 2004; Thorn and Parker, 2005). However, FM 4-64 loading was fourfold slower in persistent than in transient type II events (see also Stenovec et al., 2004). Thus, the spH signal may persist because of a rapidly flickering fusion pore, which kinetically restricts the permeation of FM 4-64 dye and possibly hormone molecules (Staal et al., 2004; Stenovec et al., 2004).

\section{Resting vesicles have narrow fusion pores that may not expand without stimulation}

Our findings suggest that exocytosis of vesicles at rest does not necessarily lead to cargo release. More than half of the vesicles entering spontaneous fusion have fusion pores with subnanometer diameters $(<0.5 \mathrm{~nm})$, too narrow for the discharge of peptide hormones (Fig. $4 b$, Table 3 ) (Stenovec et al., 2004). In contrast, the majority $(>70 \%)$ of exocytotic events in stimulated cells exhibited a larger, FM 4-64-permeable fusion pore $(>1 \mathrm{~nm})$ (Fig. 5b, Table 2), consistent with previous fusion pore permeation studies (Barg et al., 2002; Takahashi et al., 2002; Tsuboi and Rutter, 2003; Fulop et al., 2005).

In stimulated cells, $\mathrm{spH}$ imaging revealed that fusion events were predominantly persistent (>93\%) (Fig. 5, Table 2). As in spontaneous events, we did not observe lateral diffusion of $\mathrm{spH}$ from the site of stimulated exocytotic events into the

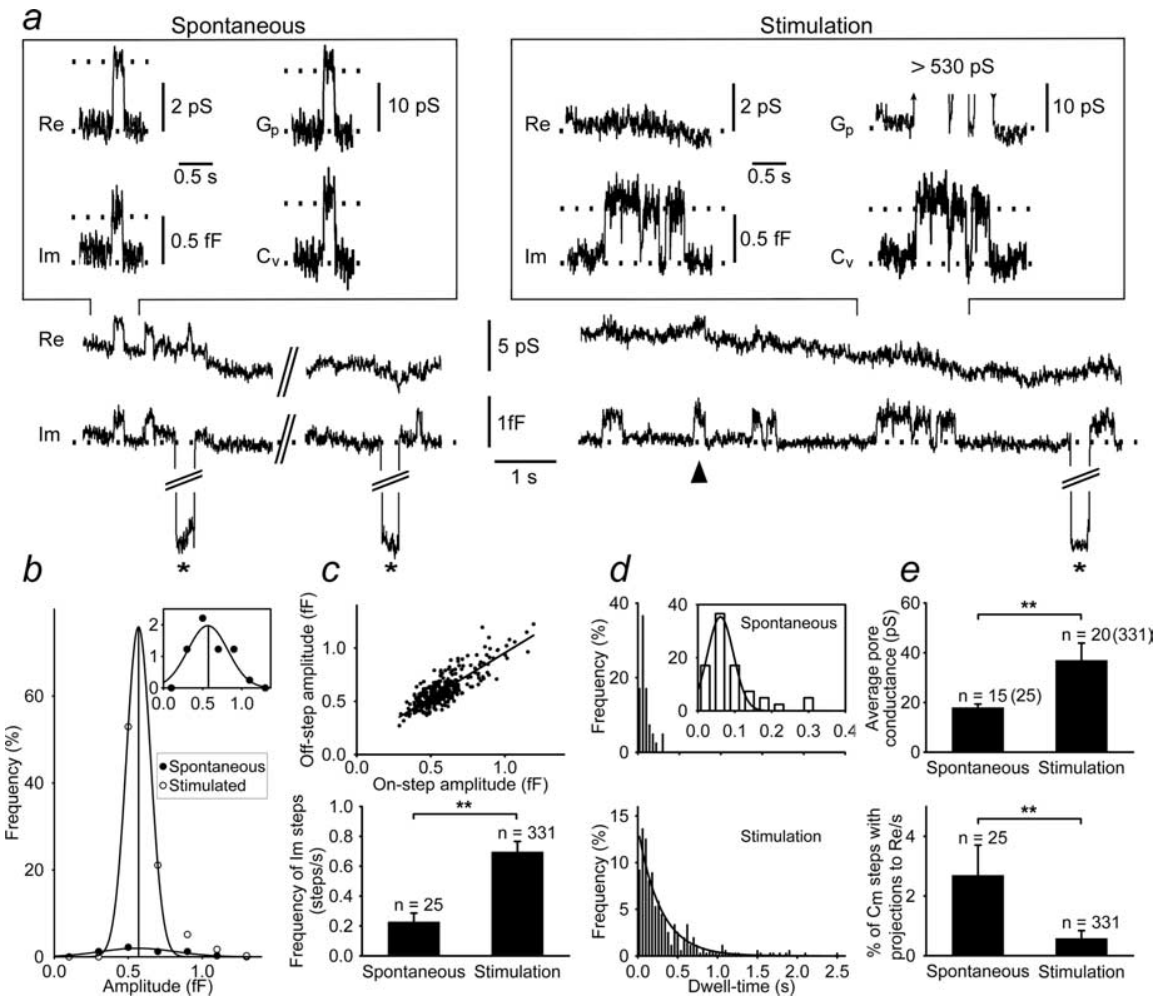

Figure 6. Fusion pore openings in cell-attached patches of a lactotroph before and after stimulation. $\boldsymbol{a}$, Examples of $R_{\mathrm{e}}$ and $I_{\mathrm{m}}$ traces under spontaneous and $100 \mathrm{~mm} \mathrm{KCl}$-stimulated conditions. $I_{\mathrm{m}}$ exhibits reversible step increases under spontaneous and stimulated conditions. Note the significant cross talk between the $I_{\mathrm{m}}$ and the $R_{\mathrm{e}}$ signals under spontaneous conditions, which diminished after stimulation (arrowhead). The calibration pulse (asterisk, $10 \mathrm{fF}$ ) does not project to the $R_{\mathrm{e}}$ signal, indicating the correct phase angle setting of the lock-in amplifier. Expanded segments show individual transient events before and after stimulation. Also shown are $G_{\mathrm{p}}$ and $C_{\mathrm{v}}$ calculated from $I_{\mathrm{m}}$ and $R_{\mathrm{e}}$ (see Materials and Methods). Insets on the right indicate fusion pore opening in which $G_{\mathrm{p}}$ was likely $>530 \mathrm{pS}$ (maximal $G_{\mathrm{p}}$ measured), because a change in $R_{\mathrm{e}}$ was not associated with the $I_{\mathrm{m}}$ signal of the transient fusion pore event. $\boldsymbol{b}$, Distribution of amplitudes of transient capacitance fusion events before and after stimulation. The curves show Gaussian fits with the mean values: $0.57 \pm 0.05 \mathrm{fF}(n=25)$ for spontaneous events and $0.57 \pm 0.04 \mathrm{fF}(n=331)$ for stimulated events ( $p=0.998$ ). The inset shows the distribution of spontaneous events on an expanded ordinate scale. $c$, 0 ccurrence of transient fusion events. A plot of capacitance on-steps versus off-steps (top) revealed a high correlation coefficient $(r)$ between the two measures $(r=0.82)$. The line represents the linear fit to the data with a slope near $1(0.85 \pm 0.03 ; n=356)$. The frequency of events (bottom), analyzed in 10 s epochs, increased from $0.23 \pm 0.06$ events $/ s(n=25$ events analyzed in 18 epochs) to $0.70 \pm 0.07$ events/s $(n=331$ events analyzed in 55 epochs). $\boldsymbol{d}$, Fusion pore dwell-time histograms under spontaneous and stimulated conditions. Frequency distribution of fusion pore dwell times in spontaneous events was best fitted with a Gaussian curve with the mean \pm SEM: $62 \pm 2 \mathrm{~ms}(n=25)$. After stimulation, the frequency distribution was best fitted with a single-exponential curve with the time constant of $287 \pm 0.02 \mathrm{~ms}(n=331) . e, G_{\mathrm{p}}$ analysis of transient events calculated from $R_{\mathrm{e}}$ and $I_{\mathrm{m}}$. Top, The average $G_{\mathrm{p}}$ increased from $18 \pm 1 \mathrm{pS}(n=15)$ to $37 \pm 7 \mathrm{pS}(n=20)$. Excluded are 10 spontaneous and 311 stimulated events that did not exhibit cross talk between the $I_{\mathrm{m}}$ and $R_{\mathrm{e}}$ traces. Bottom, The occurrence of transient events with cross talk between $I_{\mathrm{m}}$ and $R_{\mathrm{e}}$ traces was determined as percentages of events per second, analyzed in 10-s-long epochs (18 before and 55 after stimulation). Their occurrence decreased from $2.7 \pm 1.0 \% / \mathrm{s}(n=25)$ at rest to $0.6 \pm 0.3 \% / \mathrm{s}$ after stimulation $(n=$ 331). All diagrams apply to a representative experiment. Values are means \pm SEM. ${ }^{* *} p<0.05$.

Table 3. Dimensions of hydrated proton, small chemical molecules, and proteins

\begin{tabular}{lcll}
\hline Molecule & $\mathrm{M}_{\mathrm{w}}(\mathrm{g} / \mathrm{mol})$ & $\mathrm{XYZ}$ dimensions $(\mathrm{nm})^{a}$ & Database accession number \\
\hline Hydrated proton $\left(\mathrm{H}_{3} \mathrm{O}^{+}\right)$ & 19 & $0.1(0-\mathrm{H}) \times 0.2(\mathrm{H}-\mathrm{H}) \times 0.2(\mathrm{H}-\mathrm{H})$ & $13968-08-6(\mathrm{CAS})$ \\
HEPES & 238 & $0.5 \times 1.0 \times 0.3$ & $7365-45-9(\mathrm{CAS})$ \\
FM 4-64 & 608 & $0.9 \times 3.0 \times 0.3$ & \\
Human ANP & $\sim 3 \times 10^{3}$ & $2.1 \times 2.1 \times 1.1$ & 1ANP (PDB) (Cunningham et al., 1994) \\
GFP mutant & $\sim 27 \times 10^{3}$ & $3.8 \times 5.1 \times 3.6$ & 2EM0 (PDB) (Palm et al., 1997) \\
Human prolactin & $\sim 23 \times 10^{3}$ & $5.2 \times 6.4 \times 3.3$ & 1RW5 (PDB) (Teilum et al., 2005)
\end{tabular}

0-H, Oxygen atom to hydrogen atom; $\mathrm{H}-\mathrm{H}$, between two hydrogen atoms; $\mathrm{CAS}$, Chemical Abstracts Service numbers for small chemical molecules; PDB, Protein Data Bank numbers for proteins; ANP, atrial natriuretic peptide; GFP, green fluorescent protein.

${ }^{a}$ XYZ dimensions of molecules were measured with a Pymol Molecular Graphics System.

${ }^{b}$ Three-dimensional model of FM 4-64 was obtained with MDL ISIS/Draw (version 2.5) and a Pymol Molecular Graphics System. 
plasma membrane (data not shown) (Tsuboi and Rutter, 2003), indicating that stimulated vesicle exocytosis likely occurred in a non-full-collapse manner (Graham et al., 2002; Taraska et al., 2003; Tsuboi and Rutter, 2003; Thorn and Parker, 2005), not as complete vesicle fusion (Takahashi et al., 2002; Fulop et al., 2005; Elhamdani et al., 2006). Moreover, the so-called persistent events observed in optical studies very likely reflect repetitive transient fusion pore openings we observed in capacitance recordings before (Fig. 6a, left) (Stenovec et al., 2004) and after (Fig. 6a, right) stimulation and are not a consequence of a persistently open fusion pore with a long lifetime (Ohara-Imaizumi et al., 2002). Estimated mean burst duration of $C_{\mathrm{m}}$ steps of single vesicle flickers before final endocytosis was $>100 \mathrm{~s}$ in both spontaneous and stimulated events (data not shown), which is consistent with the time courses obtained in the optical studies for the duration of persistent events (Table 1). Optical monitoring of fusion dynamics is limited by the characteristics of the $\mathrm{spH}$ construct. In particular, the effect of fusion pore closure is poorly reflected in these measurements because of reacidification, which is, compared with the fusion pore closure observed as an off-step in capacitance measurements (Fig. $6 a$ ), rather slow $[\tau=4-5$ s for synaptic vesicles (Atluri and Ryan, 2006)] (Table 1, transient events), explaining why we rarely observed multiple exocytotic events with optical monitoring (Fig. $2 a$, insets). Both sets of results support the view that a narrow fusion pore widens on stimulation. Furthermore, experimental data indicate that transient exocytosis is the predominant form of secretory activity in both resting (Table 1; Fig. $6 a$, left) and stimulated (Fig. $6 a$, right) lactotrophs.

Capacitance measurements of spontaneous and stimulated fusion events of a single vesicle (Fig. 6) revealed that transient vesicle fusions occur fourfold more frequently after stimulation with a twofold longer fusion pore dwell time (Sun et al., 2002). However, the fraction of events with lowest measurable fusion pore conductance decreased by almost $80 \%(2.7 \%$ to $0.6 \%$ of events with measurable $G_{\mathrm{p}}$ per second), reflecting wider pore diameters after stimulation in the majority of transient fusion events. Therefore, a stimulus may activate already fused vesicles (unproductive exocytosis), in which only a narrow fusion pore diameter prevents cargo discharge (Fig. $4 b$, Table 3), resulting in productive exocytosis (discharge of vesicle cargo). Stimulus thus prolongs the effective opening of the fusion pore and expands its diameter, enabling hormone secretion. These results are consistent with vesicle discharge mechanisms after fusion (Hartmann and Lindau, 1995; Rahamimoff and Fernandez, 1997; Fulop et al., 2005; Michael et al., 2006).

\section{References}

Alvarez de Toledo G, Fernández-Chacón R, Fernández J (1993) Release of secretory products during transient vesicle fusion. Nature 363:554-558.

Angleson J, Cochilla A, Kilic G, Nussinovitch I, Betz W (1999) Regulation of dense core release from neuroendocrine cells revealed by imaging single exocytic events. Nat Neurosci 2:440-446.

Atluri P, Ryan T (2006) The kinetics of synaptic vesicle reacidification at hippocampal nerve terminals. J Neurosci 26:2313-2320.

Barg S, Olofsson C, Schriever-Abeln J, Wendt A, Gebre-Medhin S, Renström E, Rorsman P (2002) Delay between fusion pore opening and peptide release from large dense-core vesicles in neuroendocrine cells. Neuron 33:287-299.

Ben-Tabou S, Keller E, Nussinovitch I (1994) Mechanosensitivity of voltage-gated calcium currents in rat anterior pituitary cells. J Physiol (Lond) 476:29-39.

Ceccarelli B, Hurlbut W, Mauro A (1973) Turnover of transmitter and synaptic vesicles at the frog neuromuscular junction. J Cell Biol 57:499-524.

Cochilla AV, Angleson JK, Betz WJ (2000) Differential regulation of granule-to-granule and granule-to-plasma membrane fusion during secretion from rat pituitary lactotrophs. J Cell Biol 150:839-848.
Cunningham B, Lowe D, Li B, Bennett B, Wells J (1994) Production of an atrial natriuretic peptide variant that is specific for type A receptor. EMBO J 13:2508-2515.

Deitcher D, Ueda A, Stewart B, Burgess R, Kidokoro Y, Schwarz T (1998) Distinct requirements for evoked and spontaneous release of neurotransmitter are revealed by mutations in the Drosophila gene neuronalsynaptobrevin. J Neurosci 18:2028-2039.

Elhamdani A, Palfrey H, Artalejo C (2001) Quantal size is dependent on stimulation frequency and calcium entry in calf chromaffin cells. Neuron 31:819-830.

Elhamdani A, Azizi F, Artalejo C (2006) Double patch clamp reveals that transient fusion (kiss-and-run) is a major mechanism of secretion in calf adrenal chromaffin cells: high calcium shifts the mechanism from kissand-run to complete fusion. J Neurosci 26:3030-3036.

Fesce R, Grohovaz F, Valtorta F, Meldolesi J (1994) Neurotransmitter release: fusion or "kiss-and-run"? Trends Cell Biol 4:1-4.

Fulop T, Radabaugh S, Smith C (2005) Activity-dependent differential transmitter release in mouse adrenal chromaffin cells. J Neurosci 25:7324-7332.

Gandhi S, Stevens C (2003) Three modes of synaptic vesicular recycling revealed by single-vesicle imaging. Nature 423:607-613.

Graham M, O'Callaghan D, McMahon H, Burgoyne R (2002) Dynamindependent and dynamin-independent processes contribute to the regulation of single vesicle release kinetics and quantal size. Proc Natl Acad Sci USA 99:7124-7129.

Hartmann J, Lindau M (1995) A novel Ca(2+)-dependent step in exocytosis subsequent to vesicle fusion. FEBS Lett 363:217-220.

He L, Wu X, Mohan R, Wu L (2006) Two modes of fusion pore opening revealed by cell-attached recordings at a synapse. Nature 444:102-105.

Heuser J, Reese T (1973) Evidence for recycling of synaptic vesicle membrane during transmitter release at the frog neuromuscular junction. J Cell Biol 57:315-344.

Katz B (1969) The release of neural transmitter substances. Liverpool, UK: Liverpool UP.

Klyachko V, Jackson M (2002) Capacitance steps and fusion pores of small and large-dense-core vesicles in nerve terminals. Nature 418:89-92.

Kreft M, Milisav I, Potokar M, Zorec R (2004) Automated high through-put colocalization analysis of multichannel confocal images. Comput Methods Programs Biomed 74:63-67.

Lindau M, Almers W (1995) Structure and function of fusion pores in exocytosis and ectoplasmic membrane fusion. Curr Opin Cell Biol 7:509-517.

Lindau M, Alvarez de Toledo G (2003) The fusion pore. Biochim Biophys Acta 1641:167-173.

Lollike K, Lindau M (1999) Membrane capacitance techniques to monitor granule exocytosis in neutrophils. J Immunol Methods 232:111-120.

Malgaroli A, Ting A, Wendland B, Bergamaschi A, Villa A, Tsien R, Scheller R (1995) Presynaptic component of long-term potentiation visualized at individual hippocampal synapses. Science 268:1624-1628.

Michael D, Cai H, Xiong W, Ouyang J, Chow R (2006) Mechanisms of peptide hormone secretion. Trends Endocrinol Metab 17:408-415.

Miesenböck G, De Angelis D, Rothman J (1998) Visualizing secretion and synaptic transmission with $\mathrm{pH}$-sensitive green fluorescent proteins. Nature 394:192-195.

Neher E, Marty A (1982) Discrete changes of cell membrane capacitance observed under conditions of enhanced secretion in bovine adrenal chromaffin cells. Proc Natl Acad Sci USA 79:6712-6716.

Ohara-Imaizumi M, Nakamichi Y, Tanaka T, Katsuta H, Ishida H, Nagamatsu S (2002) Monitoring of exocytosis and endocytosis of insulin secretory granules in the pancreatic beta-cell line MIN6 using pH-sensitive green fluorescent protein (pHluorin) and confocal laser microscopy. Biochem J 363:73-80.

Palm G, Zdanov A, Gaitanaris G, Stauber R, Pavlakis G, Wlodawer A (1997) The structural basis for spectral variations in green fluorescent protein. Nat Struct Biol 4:361-365.

Pelkmans L, Zerial M (2005) Kinase-regulated quantal assemblies and kissand-run recycling of caveolae. Nature 436:128-133.

Perrais D, Kleppe I, Taraska J, Almers W (2004) Recapture after exocytosis causes differential retention of protein in granules of bovine chromaffin cells. J Physiol (Lond) 560:413-428.

Rahamimoff R, Fernandez J (1997) Pre- and postfusion regulation of transmitter release. Neuron 18:17-27. 
Richards D, Bai J, Chapman E (2005) Two modes of exocytosis at hippocampal synapses revealed by rate of FM1-43 efflux from individual vesicles. J Cell Biol 168:929-939.

Roos A, Boron W (1981) Intracellular pH. Physiol Rev 61:296-434.

Ryan T, Reuter H, Smith S (1997) Optical detection of a quantal presynaptic membrane turnover. Nature 388:478-482.

Sankaranarayanan S, Ryan T (2000) Real-time measurements of vesicleSNARE recycling in synapses of the central nervous system. Nat Cell Biol 2:197-204.

Sara Y, Virmani T, Deák F, Liu X, Kavalali E (2005) An isolated pool of vesicles recycles at rest and drives spontaneous neurotransmission. Neuron 45:563-573.

Schoch S, Deák F, Königstorfer A, Mozhayeva M, Sara Y, Südhof T, Kavalali E (2001) SNARE function analyzed in synaptobrevin/VAMP knockout mice. Science 294:1117-1122.

Spruce A, Breckenridge L, Lee A, Almers W (1990) Properties of the fusion pore that forms during exocytosis of a mast cell secretory vesicle. Neuron 4:643-654.

Staal R, Mosharov E, Sulzer D (2004) Dopamine neurons release transmitter via a flickering fusion pore. Nat Neurosci 7:341-346.

Stenovec M, Kreft M, Poberaj I, Betz W, Zorec R (2004) Slow spontaneous secretion from single large dense-core vesicles monitored in neuroendocrine cells. FASEB J 18:1270-1272.

Stenovec M, Poberaj I, Kreft M, Zorec R (2005) Concentration-dependent staining of lactotroph vesicles by FM 4-64. Biophys J 88:2607-2613.

Stevens C, Williams J (2000) "Kiss and run" exocytosis at hippocampal synapses. Proc Natl Acad Sci USA 97:12828-12833.
Sun J, Wu X, Wu L (2002) Single and multiple vesicle fusion induce different rates of endocytosis at a central synapse. Nature 417:555-559.

Takahashi N, Kishimoto T, Nemoto T, Kadowaki T, Kasai H (2002) Fusion pore dynamics and insulin granule exocytosis in the pancreatic islet. Science 297:1349-1352.

Taraska J, Perrais D, Ohara-Imaizumi M, Nagamatsu S, Almers W (2003) Secretory granules are recaptured largely intact after stimulated exocytosis in cultured endocrine cells. Proc Natl Acad Sci USA 100:2070-2075.

Teilum K, Hoch J, Goffin V, Kinet S, Martial J, Kragelund B (2005) Solution structure of human prolactin. J Mol Biol 351:810-823.

Thorn P, Parker I (2005) Two phases of zymogen granule lifetime in mouse pancreas: ghost granules linger after exocytosis of contents. J Physiol (Lond) 563:433-442.

Tsuboi T, Rutter G (2003) Multiple forms of "kiss-and-run" exocytosis revealed by evanescent wave microscopy. Curr Biol 13:563-567.

Walker A, Farquhar M (1980) Preferential release of newly synthesized prolactin granules is the result of functional heterogeneity among mammotrophs. Endocrinology 107:1095-1104.

Weiss TF (1996) Cellular biophysics: transport. Cambridge, MA: MIT.

Wucherpfennig T, Wilsch-Bräuninger M, González-Gaitán M (2003) Role of Drosophila Rab5 during endosomal trafficking at the synapse and evoked neurotransmitter release. J Cell Biol 161:609-624.

Zorec R, Sikdar S, Mason W (1991) Increased cytosolic calcium stimulates exocytosis in bovine lactotrophs. Direct evidence from changes in membrane capacitance. J Gen Physiol 97:473-497. 